\title{
Communication \\ Determination of Phenolic Compounds Using HPLC-UV Method in Wild Fruit Species
}

\author{
Ana-Maria Stoenescu ${ }^{1}$ (D), Ion Trandafir ${ }^{2}$ and Sina Cosmulescu ${ }^{3, *(D)}$ \\ 1 Department of Biology \& Environmental Engineering, Horticulture Faculty, University of Craiova, \\ 200585 Craiova, Romania; anamaria_stoenescu@yahoo.com \\ 2 Faculty of Chemistry, University of Craiova, 200585 Craiova, Romania; nelutrandafir@yahoo.com \\ 3 Department of Horticulture \& Food Science, Horticulture Faculty, University of Craiova, \\ 200585 Craiova, Romania \\ * Correspondence: sinacosmulescu@hotmail.com
}

check for updates

Citation: Stoenescu, A.-M.; Trandafir, I.; Cosmulescu, S. Determination of

Phenolic Compounds Using HPLC-UV Method in Wild Fruit Species. Horticulturae 2022, 8, 84. https://doi.org/10.3390/ horticulturae 8020084

Academic Editor: Massimo Lucarini

Received: 27 December 2021

Accepted: 15 January 2022

Published: 18 January 2022

Publisher's Note: MDPI stays neutral with regard to jurisdictional claims in published maps and institutional affiliations.

Copyright: (c) 2022 by the authors. Licensee MDPI, Basel, Switzerland. This article is an open access article distributed under the terms and conditions of the Creative Commons Attribution (CC BY) license (https:// creativecommons.org/licenses/by/ $4.0 /)$.

\begin{abstract}
Plant parts of some spontaneous fruit species were analyzed by HPLC-UV method to determine their content in phenolic compounds. Buds, leaves, flowers, and fruits were harvested from 11 wild fruit species of medicinal, food, and therapeutic interest: European crab apple, European wild pear, blackthorn, dog rose, elder, dewberry, wild blackberry, cornelian cherry, red hawthorn, black hawthorn, and green strawberry. The studied species were analyzed for the presence and amount of phenolic compounds: flavonoids from the subclasses flavanols (catechin hydrate and epicatechin) and flavonols (rutin, myricetin, quercetin, and kaempferol) together with phenolic acids belonging to the hydroxybenzoic acid subclass (ellagic, gallic, syringic, vanillic, and salicylic) and hydroxycinnamic acids (caffeic, ferulic, sinapic, p-coumaric, neochlorogenic, and chlorogenic). The obtained results confirm the presence of bioactive compounds in different plant parts in wild fruit species. The variability identified from one species to another, the different compositions of phenols within the species, provides useful data on the role of these plant parts in the human body.
\end{abstract}

Keywords: flavonoids; flowers; HPLC; leaves; phenolic acids; wild fruits

\section{Introduction}

Phenolic compounds represent a class of intensively studied bioactive molecules, with numerous health benefits, used in the pharmaceutical industry for the treatment of various diseases; in the food industry as additives, natural preservatives, and dyes; in the cosmetic industry due to its antimicrobial, antioxidant, and anti-inflammatory properties, offering protection against UV radiation; in the textile industry as natural dye; and in the packaging industry as a quality indicator [1]. Wild fruit species are of particular importance due to their properties and bioactive compounds [2] present in all plant parts (root, bark, buds, flowers, leaves, fruits, seeds, and kernels). Their usefulness in food, medicine, and therapy has long been researched, and the role of consuming fresh or processed fruits in various forms, as well as the use of other plant parts in treating various conditions, has attracted attention since ancient times [3]. Studies to date have shown that rosehip (Rosa canina) extracts contain phenolic acids, proanthocyanidins, tannins, flavonoids, saturated and unsaturated fatty acids, phospholipids, minerals, galactolipids, and carotenoids $[4,5]$. Black hawthorn (Crataegus pentagyna) leaves and flowers contain high amounts of polyphenols with a beneficial antioxidant effect for the treatment of cardiovascular disorders [6]. Crataegus monogyna is a species with a high content of polyphenols with an antioxidant role, and the plant parts can be used either individually or in a mixture as a diuretic, antispasmodic, hepatoprotective, cardiotonic, and antioxidant [7]. Although blackthorns (Prunus spinosa) have a sour taste, they possess antibacterial and anti-inflammatory properties and are a rich source of antioxidants, vitamin C, polyphenols, and anthocyanins [8], being also used in the food preparation of jams or consumed fresh for the treatment of 
dysentery [9]. Malus sylvestris is a natural resource of bioactive compounds, polyphenols, and antioxidants, in some cases with a much higher content than Malus domestica [10]. European wild pear (Pyrus pyraster) has a high content of polyphenols, antioxidants, and flavonoids according to Savić et al. [11]. Sambucus nigra is a species rich in anthocyanins, vitamin A, B6, C, calcium, iron, tannins, and essential oils, and traditional medicine parts of the plant are used for their diuretic and laxative properties in treating various stomach ailments, sinus congestion, rheumatism, respiratory disorders, bronchitis, sore throat, cold, cough, asthma, constipation, diarrhea, dermatological conditions, hemorrhoids, pneumonia, edema, and oral disorders [12,13]. The genus Rubus is of food importance [9,14] used in pastry, salads, juices, jams, alcoholic beverages, syrups, teas, dyes, and natural preservatives; they are known for their nutritional (vitamins, folic acid, malic, succinic, oxalic, lactic, iron, magnesium, lipids, minerals, flavonoids, essential oils) and medicinal (antioxidant, tonic, anticancer, anti-inflammatory, antimicrobial, antiviral, blood pressure regulation, used in treatment of gastrointestinal, pulmonary, renal, abscess disorders) value. Cornelian cherry (Cornus mas) has a high content of antioxidants, so it possesses intense antioxidant activity, flavonoids $[15,16]$, polyphenols, tannins, sugars, pectin, anthocyanins, iridoids, ursolic acid, carotenoids, carbohydrates, and organic acids [17]. According to Nizioł-Łukaszewska et al. [18], the cornelian cherry fruit extract can be used successfully in the cosmetics industry due to its antioxidant properties. The fruits, leaves, flowers, and buds of spontaneous fruit species are traditionally used in the preparation of teas for the treatment of various ailments, in the form of tinctures, decoctions, and poultices, but also in culinary preparations, such as in jams, compotes, juices, vinegars, and alcoholic beverages. It is important to know the presence and the amount of each phenolic compound so that it can be used in the most beneficial way possible in the human body. This research aims to identify and quantify bioactive compounds from plant parts of wild fruit species that are adapted to climatic conditions and the ecosystem they belong to; are natural, without any chemical treatments; and can be a source of high-quality nutraceuticals.

\section{Materials and Methods}

\subsection{Wild Fruit Species Samples}

For this study, fruit species from spontaneous flora were selected, individuals belonging to populations from different areas of a forest ecosystem, the Bratovoesti forest $\left(44^{\circ} 05^{\prime} 29.3^{\prime \prime} \mathrm{N} 23^{\circ} 54^{\prime} 00.2^{\prime \prime}\right.$ E) and its immediate vicinity, Dolj County, Oltenia Region, Romania: Crataegus monogyna (L.) Jacq. - red hawthorn, Crataegus pentagyna (L.) Waldst. et Kit.—black hawthorn, Pyrus pyraster (L.) Burgsd.—European wild pear, Malus sylvestris (L.) Mill.—European crab apple, Prunus spinosa (L.) —blackthorn/sloe, Rosa canina (L.)—dog rose, Sambucus nigra (L.) —elder, Rubus caesius (L.)—dewberry, Rubus fruticosus (L.)-wild blackberry, Fragaria viridis (L.) Weston-green strawberry, and Cornus mas (L.) - cornelian cherry. These species were chosen because of their importance in food, medicine, and therapy and their traditional use over time. The parts of the plant were harvested by hand from several individuals within the same species in order to have a high degree of homogeneity, in the order of vegetation phenophases as follows: flowering buds $(\mathrm{BBCH}$ $51)$, leaves and flowers (BBCH 65), and fruits ( $\mathrm{BBCH} 87)$. The samples were carried to the laboratory and dried in an oven at $50{ }^{\circ} \mathrm{C}$ until the weight was stabilized on the balance.

\subsection{Sample Preparation}

To determine the phenolic compounds, $1 \mathrm{~g}$ of dry sample (skin and pulp of the fruit, buds, flowers, leaves) was weighed with a Radwag AS 220 RD analytical balance into centrifuge tubes over which $25 \mathrm{~mL} \mathrm{MeOH}(100 \%)$ was added. The resulting mixtures were vortexed, then placed in a Fungilab ultrasonic bath for $30 \mathrm{~min}$ at $25^{\circ} \mathrm{C}$. The samples were stored overnight in a refrigerator $\left(3^{\circ} \mathrm{C}\right)$, after which they were placed for another $30 \mathrm{~min}$ in the ultrasonic bath and then centrifuged (Eppendorf Centrifuge $5430 \mathrm{R}$ ) for $5 \mathrm{~min}$ at $4000 \times g \mathrm{rpm}$, filtered, and placed in HPLC for analysis based on phenolic compound standards purchased from Sigma-Aldrich. 


\subsection{HPLC Analyses}

Analysis of phenolic compounds was performed on an ultra-high performance liquid chromatograph (UltiMate 3000 XRS Liquid Chromatograph, Thermo Scientific, Waltham, USA) combined with a Dionex UltiMate 3000 XRS Autosampler, an XRS pump, and an RS Diode UV-VIS matrix detector, in the order of appearance on the chromatogram: gallic acid, neochlorogenic acid, (+)-catechin hydrate, chlorogenic acid, vanillic acid, caffeic acid, syringic acid, (-)-epicatechin, p-coumaric acid, ferulic acid, sinapic acid, salicylic acid, ellagic acid, rutin, myricetin, quercetin, and kaempferol. The mobile phase consisted of $1 \%$ aqueous acetic acid solution (B) and $100 \% \mathrm{MeOH}(\mathrm{C})$. The samples were eluted with the following gradient: $90 \% \mathrm{~B}$ and $10 \% \mathrm{C}$ from 0 to $6 \mathrm{~min}, 84 \% \mathrm{~B}$ and $16 \% \mathrm{C}$ from 7 to $25 \mathrm{~min}, 72 \% \mathrm{~B}$ and $28 \% \mathrm{C}$ from 26 to $37 \mathrm{~min}, 65 \% \mathrm{~B}$ and $35 \% \mathrm{C}$ from 38 to $47 \mathrm{~min}, 50 \%$ $\mathrm{B}$ and $50 \% \mathrm{C}$ from 48 to $64 \mathrm{~min}$, and $90 \% \mathrm{~B}$ and $10 \% \mathrm{C}$ from 65 to $70 \mathrm{~min}$, to restore the initial conditions, before injection of a new sample. The flow rate was $0.8 \mathrm{~mL} / \mathrm{min}$, and the injection volume was $5 \mu \mathrm{L}$. The column used was Hypersil Gold $(150 \times 4.6)$ with the temperature maintained at $25^{\circ} \mathrm{C}$. The detection of phenolic compounds was performed by UV absorption at $\lambda=278 \mathrm{~nm}$. Each compound was identified based on its retention time and by comparison with standards under the same conditions (Figure 1). All results were expressed in $\mathrm{mg} / 100 \mathrm{~g} \mathrm{DW}$, and they represent the mean and standard deviation of three determinations.

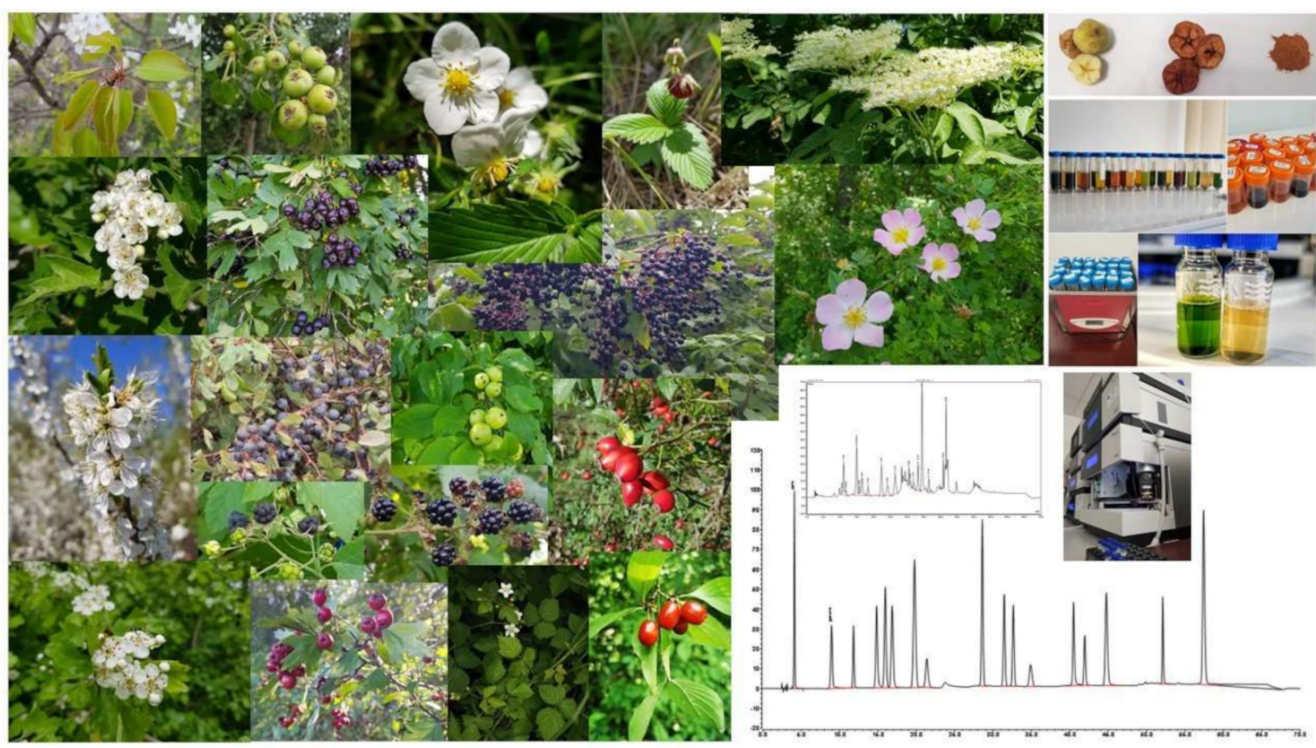

Figure 1. Diagram of the plant materials used and the general procedure.

\section{Results}

Phenolic compounds are important due to their properties against many diseases but also due to their applicability in many other industries. The species studied were analyzed regarding the presence and amount of phenolic compounds, that is, flavonoids from the subclasses flavanols ((+)-catechin hydrate and (-)-epicatechin) and flavonols (rutin, myricetin, quercetin, and kaempferol) together with phenolic acids belonging to the subclass of hydroxybenzoic acids (ellagic, gallic, syringic, vanillic, and salicylic) and hydroxycinnamic acids (caffeic, ferulic, sinapic, p-coumaric, neochlorogenic, and chlorogenic). Regarding the flavonoid content (Table 1) of the plant parts of the studied wild fruit species, among the flavanols, catechin hydrate was identified to be at the highest amount in cornelian cherry fruits (268.16 mg/100 g DW), dog rose leaves (545.16 mg/100 g DW), and blackthorn flowers (494.94 mg/100 g DW), while epicatechin, at the highest amount, was identified in red hawthorn fruits $(143.25 \mathrm{mg} / 100 \mathrm{~g} \mathrm{DW})$ and green strawberry leaves and flowers (778.11 and $120.03 \mathrm{mg} / 100 \mathrm{~g} \mathrm{DW}$, respectively). 
Table 1. Flavonoid content of studied wild fruit species in different plant parts.

\begin{tabular}{|c|c|c|c|c|c|c|c|}
\hline \multirow{2}{*}{ Species/Part } & & \multicolumn{6}{|c|}{ Flavonoids mg/100 g DW * } \\
\hline & & $C^{* *}$ & EC & RUT & MYR & QCT & $\mathbf{K P}$ \\
\hline \multirow{2}{*}{ Malus sylvestris } & $\mathrm{Fr}$ & $144.62 \pm 21.36$ & n.d. & n.d. & $46.22 \pm 2.64$ & n.d. & n.d. \\
\hline & $\mathrm{Lv}$ & $19.42 \pm 1.14$ & n.d. & $351.15 \pm 19.15$ & $232.36 \pm 14.25$ & n.d. & $14.52 \pm 0.10$ \\
\hline \multirow{2}{*}{ Pyrus pyraster } & $\mathrm{Fr}$ & n.d. & n.d. & n.d. & n.d. & n.d. & n.d. \\
\hline & $\mathrm{Lv}$ & $44.93 \pm 3.25$ & $8.64 \pm 0.56$ & $231.88 \pm 10.24$ & $13.29 \pm 1.10$ & n.d. & n.d. \\
\hline \multirow{3}{*}{ Rosa canina } & Fr & n.d. & n.d. & n.d. & n.d. & n.d. & n.d. \\
\hline & $\mathrm{Lv}$ & $545.16 \pm 15.47$ & n.d. & $565.29 \pm 26.10$ & $88.90 \pm 4.30$ & n.d. & n.d. \\
\hline & $\mathrm{Fl}$ & $158.29 \pm 11.36$ & $48.26 \pm 2.65$ & $420.09 \pm 16.28$ & $57.01 \pm 2.48$ & n.d. & $4.68 \pm 0.05$ \\
\hline \multirow{3}{*}{ Crataegus pentagyna } & $\mathrm{Fr}$ & $13.63 \pm 1.20$ & $37.28 \pm 1.25$ & $34.56 \pm 1.10$ & $26.25 \pm 1.25$ & n.d. & n.d. \\
\hline & $\mathrm{Lv}$ & $8.59 \pm 0.50$ & n.d. & $233.65 \pm 10.47$ & $53.02 \pm 1.70$ & n.d. & n.d. \\
\hline & $\mathrm{Fl}$ & $225.10 \pm 21.42$ & n.d. & $140.28 \pm 14.84$ & $247.69 \pm 14.56$ & n.d. & n.d. \\
\hline \multirow{3}{*}{ Crataegus monogyna } & $\mathrm{Fr}$ & $31.18 \pm 4.09$ & $143.25 \pm 10.64$ & $43.50 \pm 2.25$ & $6.43 \pm 0.50$ & n.d. & $5.12 \pm 0.05$ \\
\hline & $\mathrm{Lv}$ & $62.40 \pm 6.49$ & n.d. & $153.19 \pm 4.56$ & $17.21 \pm 0.80$ & n.d. & n.d. \\
\hline & $\mathrm{Fl}$ & $69.38 \pm 6.23$ & n.d. & $49.27 \pm 2.31$ & $35.34 \pm 2.84$ & n.d. & n.d. \\
\hline \multirow{3}{*}{ Sambucus nigra } & $\mathrm{Fr}$ & n.d. & n.d. & $270.29 \pm 15.70$ & $10.92 \pm 0.64$ & $8.11 \pm 0.10$ & n.d. \\
\hline & $\mathrm{Lv}$ & $238.25 \pm 17.45$ & $5.49 \pm 0.01$ & $131.82 \pm 8.45$ & $10.98 \pm 0.24$ & n.d. & n.d. \\
\hline & $\mathrm{Fl}$ & $87.76 \pm 4.58$ & n.d. & $769.10 \pm 21.84$ & $147.91 \pm 12.35$ & n.d. & n.d. \\
\hline \multirow{3}{*}{ Rubus caesius } & $\mathrm{Fr}$ & n.d. & $26.07 \pm 2.63$ & $3.04 \pm 0.10$ & n.d. & n.d. & n.d. \\
\hline & $\mathrm{Lv}$ & $246.99 \pm 10.20$ & $16.07 \pm 0.45$ & $2.79 \pm 0.01$ & $50.57 \pm 1.35$ & n.d. & n.d. \\
\hline & $\mathrm{Fl}$ & $34.36 \pm 4.26$ & $16.15 \pm 1.84$ & n.d. & $30.30 \pm 1.28$ & $18.68 \pm 1.49$ & n.d. \\
\hline \multirow{3}{*}{ Rubus fruticosus } & $\mathrm{Fr}$ & n.d. & $5.80 \pm 0.54$ & n.d. & n.d. & n.d. & n.d. \\
\hline & $\mathrm{Lv}$ & $50.06 \pm 2.15$ & $14.48 \pm 0.21$ & $64.29 \pm 2.31$ & $12.47 \pm 0.70$ & n.d. & n.d. \\
\hline & $\mathrm{Fl}$ & $221.27 \pm 19.87$ & $88.79 \pm 1.26$ & $32.37 \pm 1.64$ & $51.32 \pm 2.84$ & n.d. & n.d. \\
\hline \multirow{3}{*}{ Fragaria viridis } & $\mathrm{Fr}$ & $1.27 \pm 0.25$ & n.d. & n.d. & n.d. & n.d. & n.d. \\
\hline & $\mathrm{Lv}$ & $311.76 \pm 21.35$ & $778.11 \pm 15.15$ & $242.36 \pm 14.20$ & $66.98 \pm 2.15$ & n.d. & n.d. \\
\hline & $\mathrm{Fl}$ & $25.85 \pm 2.54$ & $120.03 \pm 10.64$ & n.d. & $7.50 \pm 0.03$ & n.d. & n.d. \\
\hline \multirow{2}{*}{ Cornus mas } & $\mathrm{Fr}$ & $268.16 \pm 16.97$ & n.d. & n.d. & n.d. & n.d. & n.d. \\
\hline & $\mathrm{Lv}$ & $105.57 \pm 9.10$ & $13.98 \pm 0.24$ & $191.81 \pm 21.10$ & $27.28 \pm 1.15$ & n.d. & n.d. \\
\hline \multirow{4}{*}{ Prunus spinosa } & $\mathrm{Fr}$ & n.d. & n.d. & n.d. & n.d. & n.d. & n.d. \\
\hline & $\mathrm{Lv}$ & $205.93 \pm 11.48$ & n.d. & $114.52 \pm 7.15$ & $127.62 \pm 9.46$ & n.d. & n.d. \\
\hline & $\mathrm{Fl}$ & $494.74 \pm 42.15$ & n.d. & $14.50 \pm 0.67$ & $6.15 \pm 0.10$ & $32.56 \pm 1.65$ & $5.64 \pm 0.08$ \\
\hline & $\mathrm{Bd}$ & n.d. & $18.26 \pm 14.23$ & n.d. & $56.70 \pm 1.23$ & $99.19 \pm 4.37$ & n.d. \\
\hline
\end{tabular}

* Values represent the average of 3 determinations. ${ }^{* *} \mathrm{Fr}$-fruits, Lv-leaves, Fl—flowers, Bd-buds, C- $(+)$ catechin hydrate, EC-(-)—epicatechin, RUT—rutin, MYR-myricetin, QCT-quercetin, KP-kaempferol, mean \pm standard deviation, n.d.-not detected.

Of these, large amounts of rutin in fruits $(270.29 \mathrm{mg} / 100 \mathrm{~g} \mathrm{DW})$ and flowers $(769.10 \mathrm{mg} /$ $100 \mathrm{~g}$ DW) were found in elder, while dog rose leaves had the highest value of $565.29 \mathrm{mg} / 100 \mathrm{~g}$ DW. Myricetin was the most abundant compared with the rest of the samples analyzed in European crab apple, with contents of $46.22 \mathrm{mg} / 100 \mathrm{~g}$ DW in fruits and $232.36 \mathrm{mg} / 100 \mathrm{~g}$ DW in leaves, while black hawthorn flowers had the highest content of $247.69 \mathrm{mg} / 100 \mathrm{~g}$ DW. Quercetin was identified only in elderberries, dewberry flowers, and blackthorn flowers and buds, while kaempferol was identified only in red hawthorn fruits, European crab apple leaves, dog rose, and blackthorn flowers. Phenolic acids also had a high degree of variability between species (Table 2). Among the representative phenolic acids, regarding the maximum amount of gallic acid identified, elderberries and green strawberry fruits (122.14 and $122.02 \mathrm{mg} / 100 \mathrm{~g} \mathrm{DW})$, cornelian cherry leaves $(145.84 \mathrm{mg} / 100 \mathrm{~g}$ DW), and dog rose flowers $(23.77 \mathrm{mg} / 100 \mathrm{~g}$ DW) were noted. Neochlorogenic acid was identified to be at the highest amount in black hawthorn fruits $(95.57 \mathrm{mg} / 100 \mathrm{~g} \mathrm{DW})$, dog rose leaves $(88.65 \mathrm{mg} / 100 \mathrm{~g} \mathrm{DW})$, and black hawthorn flowers $(633.19 \mathrm{mg} / 100 \mathrm{~g}$ DW). Chlorogenic acid was noted in European crab apple fruits (249.78 mg/100 g DW), 
European wild pear leaves $(656.78 \mathrm{mg} / 100 \mathrm{~g}$ DW), and elderflowers $(807.42 \mathrm{mg} / 100 \mathrm{~g}$ DW). Syringic acid was identified in a single sample, namely, green strawberry leaves and flowers (131.01 and $29.05 \mathrm{mg} / 100 \mathrm{~g} \mathrm{DW}$, respectively). Salicylic acid was found in black hawthorn leaves with a value of $864.30 \mathrm{mg} / 100 \mathrm{~g}$ DW, and elderflowers with a value of $303.13 \mathrm{mg} / 100 \mathrm{~g}$ DW. The highest amount of ellagic acid was identified in green strawberry fruits (351.96 mg/100 g DW), European crab apple leaves $(2537.69 \mathrm{mg} / 100 \mathrm{~g}$ $\mathrm{DW})$, and dog rose flowers $(278.17 \mathrm{mg} / 100 \mathrm{~g}$ DW). The different compositions regarding phenolic compounds are due to different species (e.g., genetic differences), but also due to the pedoclimatic characteristics, the age of the genotypes, and the time of sampling. 
Table 2. Phenolic acid content of studied wild fruit species in different plant parts

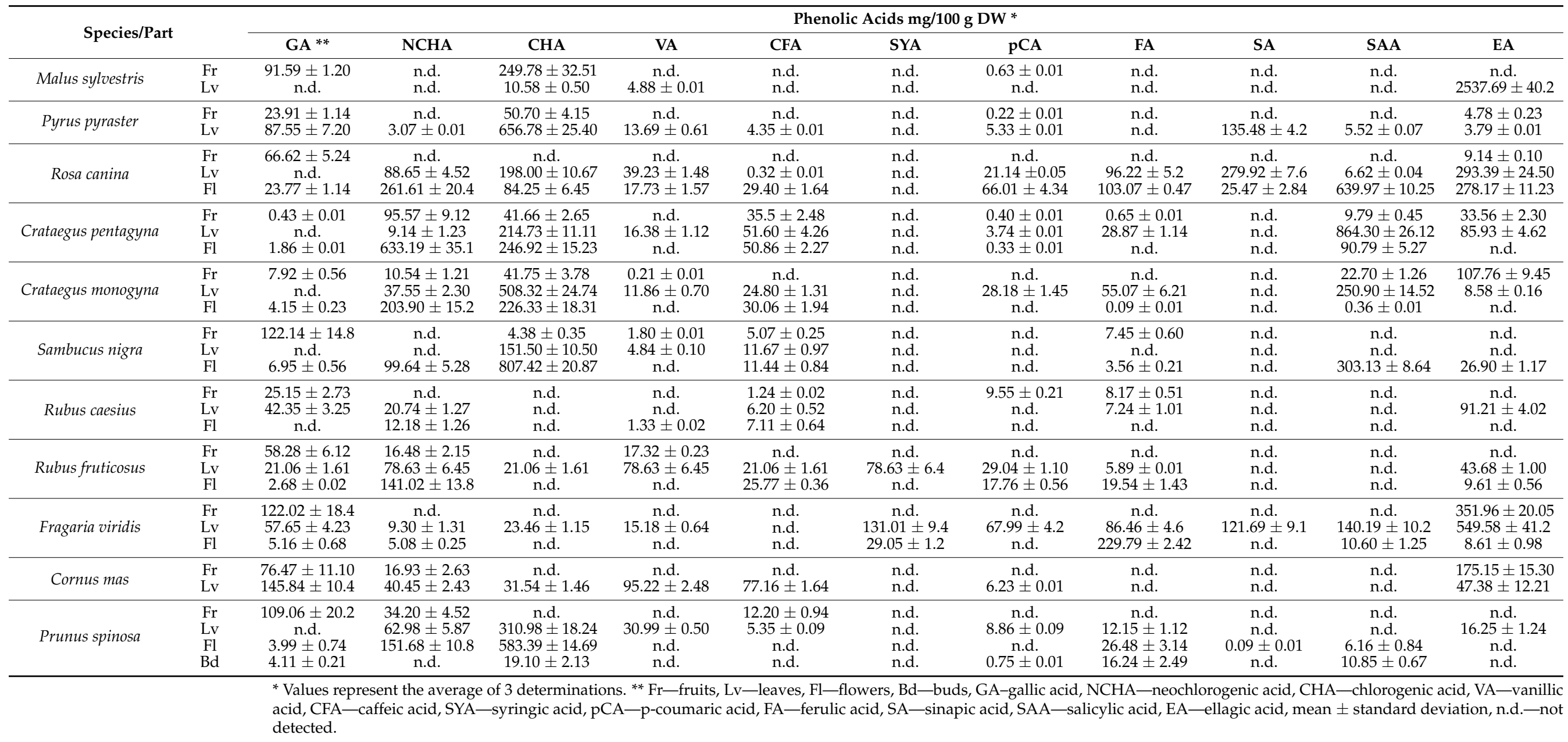




\section{Discussion}

The results obtained from this study highlight the presence of certain phenolic compounds in extracts of plant parts from spontaneous fruit species, compounds with an important role in human health. Thus, Mechchate et al. [19] cited the flavonoids catechin, epicatechin, and rutin as having a beneficial effect against diabetes, while Binang and Takuwa [20] cited rutin, myricetin, quercetin, and kaempferol as active antihypertensive flavonoids. Six flavonoids were quantified in analyzed wild fruit species (Table 1). Regarding the presence of phenolic compounds in wild fruits, Cosmulescu et al. [21] confirmed the presence of myricetin at the highest amount in cornelian cherry fruits $(30.54 \mathrm{mg} / 100 \mathrm{~g}$ FW), epicatechin in wild blackberry fruits $(226.74 \mathrm{mg} / 100 \mathrm{~g} \mathrm{FW})$, quercetin in wild blackberry fruits $(6.83 \mathrm{~g} / 100 \mathrm{~g} \mathrm{FW})$, and catechin in blackthorn fruits $(3.41 \mathrm{mg} / 100 \mathrm{~g}$ FW). For these compounds, the results obtained in this study are different, the genetic ability of the analyzed fruit species to produce these substances contributed most to their levels found in different parts of the plant, but also the associated interactions significantly contributed to the accumulation levels of the phenolic compounds. The highest amount of myricetin was found in the flower extract of C. pentagyna (247.69 mg/100 g DW), which makes this species an important source for myricetin due to its various health-promoting effects. Quercetin is a polyphenol substance with multidirectional activity in the human body [22]. As a result, $P$. spinosa could be considered an important source for this. Epicatechin is a natural flavonoid, and it has been reported to possess an immense antioxidant effect, which contributes to its therapeutic properties against a handful of ailments [23]. The largest amount of epicatechin was found in F. viridis (778.11 mg/100 g DW in leaves and $120.03 \mathrm{mg} / 100 \mathrm{~g}$ DW in flowers) (Table 1).

Additionally, Veličković et al. [24] mentioned quercetin and kaempferol as two important compounds present in blackthorn flowers, which confirms the results obtained from this study. Regarding the presence of flavonoids in different parts of the plant in S. nigra, Viapiana and Wesolowski [25] mentioned the presence in fruits, flowers, and leaves of rutin (0.44-6.45 mg/g DW in fruit infusion), myricetin (1.17-9.62 mg/g DW in flower infusion), quercetin (2.07-9.48 mg/g DW in flower infusion), and kaempferol (0.62-4.98 mg/g DW in fruit infusion). Our study showed that $S$. nigra can be an important source of flavonoids, the results are different considering the extraction method, and kaempferol was not detected in our study. Wild fruits have proven to be an important source for rutin, the highest amount identified in S. nigra (769.1 mg/100 g DW in flowers). Studies by Dawidowicz et al. [26] confirmed the presence of rutin in fruits $(0.11 \mathrm{~g} / 100 \mathrm{~g})$, flowers $(1.33 \mathrm{~g} / 100 \mathrm{~g})$, and leaves $(0.07 \mathrm{~g} / 100 \mathrm{~g})$ of $S$. nigra. Phenolic acids are biologically active molecules; they are present in a wide range of plants and have commercial value in the cosmetic, health, and medicine industries due to their antiaging, antitumor, antimicrobial, and anti-inflammatory properties. Contardi et al. [27] support the importance and role of hydroxycinnamic acids in treating dermatological conditions (burns, wound healing, psoriasis, dermatitis, inflammation) and mentioned chlorogenic acid to be beneficial for prolonging the shelf life of food due to its antibacterial and antioxidant properties. Eleven phenolic acids were quantified in different parts of the plant in the analyzed fruit species (Table 2). Gallic acid was present in most samples, with limits ranging from 0.43 (C. pentagyna fruits) to 145.84 (C. mas leaves) $\mathrm{mg} / 100 \mathrm{~g}$ DW. Gallic acid is a natural phenolic compound found in several fruits and medicinal plants and is reported to have several health-promoting effects [28]. Given its wide distribution in the analyzed species, it is considered that wild species can also be an important source for this substance. Neochlorogenic, chlorogenic, and vanillic acids were also identified in different parts of the plant (Table 2), and there were significant differences due to different wild fruit species. The highest amount of neochlorogenic acid was identified in C. pentagyna flowers $(633.19 \mathrm{mg} / 100 \mathrm{~g} \mathrm{DW})$, chlorogenic acid in S. nigra flowers (807.42 mg/100 g DW), and vanillic acid in C. mas leaves (95.22 mg/100 g DW). Oszmiański et al. [29] confirmed the presence of neochlorogenic acid (0.74 $\mathrm{mg} / \mathrm{g}$ DW) and chlorogenic acid $(0.44 \mathrm{mg} / \mathrm{g} \mathrm{DW})$ in leaf extracts of $R$. caesius species, together with ellagic acid $(1.25 \mathrm{mg} / \mathrm{g} \mathrm{DW})$ and p-coumaric acid $(0.11 \mathrm{mg} / \mathrm{g} \mathrm{DW})$, results that are relatively 
close to those obtained in this paper. Additionally, Andreotti et al. [30] confirmed the presence of chlorogenic and coumaric acids in the leaves of cultivated pear but in much larger quantities than those obtained in this paper from its wild relative. The chlorogenic acid identified in P. pyraster was close to that obtained by Li et al. [31] for fruit extracts of Pyrus spp. from China, mentioning this compound as the predominant one along with p-coumaric, vanillic, gallic, and ferulic acids (vanillic and ferulic acids were not identified in this analysis) among phenolic acids. Ellagic, caffeic, ferulic, p-coumaric, and salicylic acids were identified in a large number of samples (Table 2). The ellagic acid content ranged from 3.79 (P. pyraster leaves) to 2537.69 (M. sylvestris leaves) $\mathrm{mg} / 100 \mathrm{~g}$ DW, caffeic acid ranged from 0.32 (R. canina leaves) to 77.16 (C. mas leaves) $\mathrm{mg} / 100 \mathrm{~g} \mathrm{DW}$, and ferulic acid ranged from 0.09 (C. monogyna flowers) to 229.79 (F. viridis flowers) mg/100 g DW. Regarding the results obtained for the phenolic compounds identified in wild fruits, Demir et al. [32] confirmed gallic (12.76 $\mu \mathrm{g} / \mathrm{g} \mathrm{DW})$, catechin, chlorogenic, caffeic, coumaric, ferulic, and sinapic acids in rosehips, compared with the results obtained from this research in which only gallic and ellagic acids were identified. Regarding the phenolic compounds that are present in the fruits and leaves of $F$. viridis, the results of this study are similar to those obtained by Olennikov et al. [33], who mentioned the presence of catechin $(0.05 \mathrm{mg} / \mathrm{g} \mathrm{FW})$ in fresh ripe fruit, along with ellagic acid $(0.12 \mathrm{mg} / \mathrm{g} \mathrm{FW})$, quercetin $(0.02 \mathrm{mg} / \mathrm{g} \mathrm{FW})$, and kaempferol $(0.01 \mathrm{mg} / \mathrm{g}$ FW). Syringic and sinapic acids were identified in a few samples (plant parts), syringic acid only in R. fruticosus (leaves) and F. viridis (leaves, flowers) in amounts ranging from 29.05 to $131.01 \mathrm{mg} / 100 \mathrm{~g}$ DW. Sinapic acid was found in the leaves of P. pyraster species, in the leaves and flowers of $R$. canina species, in the leaves of $F$. viridis species, and in the flowers of $P$. spinosa species, within limits of variation between 0.09 and $279.92 \mathrm{mg} / 100 \mathrm{~g}$ DW. Syringic acid is an excellent compound to be used as a therapeutic agent in various diseases (diabetes, CVDs, cancer, cerebral ischemia, neurological damage, and liver damage), and it shows antioxidant, antimicrobial, anti-inflammatory, and antiendotoxic activities [34]. Cosmulescu et al. [22] found significant amounts of syringic and sinapic acids in wild fruit extracts of P. spinosa. Sinapic acid shows antioxidant, antimicrobial, anti-inflammatory, anticancer, and antianxiety activities [35].

\section{Conclusions}

The results obtained from this paper provide additional information and confirm the presence of bioactive compounds in different plant parts of wild fruit species and the variability identified from one species to another. Knowing the role of these products in the human body, health, and personal care, wild fruit species can have great potential in the food industry as a source of dyes and flavors but also bioactive compounds, such as phenols in food supplements or functional foods. Owing to the presence of bioactive compounds, wild fruit species can ensure the strengthening of human immunity, and therefore, they provide health protection against the adverse effects of climate change, pollution, and pandemics, such as COVID-19. Additionally, wild fruit species have the advantage of being deprived of phytosanitary treatments as part of a natural ecosystem. The quantification and optimization of the flavonoid and phenolic acid contents of these wild fruit species and their extracts will be monitored for their commercial use in foods, nutraceuticals, and cosmetics.

Author Contributions: Conceptualization, S.C. and A.-M.S.; methodology, I.T.; validation, I.T.; investigation, S.C. and A.-M.S.; data curation, S.C. and A.-M.S.; writing-original draft preparation, S.C. and A.-M.S.; writing-review and editing, S.C. All authors have read and agreed to the published version of the manuscript.

Funding: This research received no external funding.

Institutional Review Board Statement: Not applicable.

Informed Consent Statement: Not applicable.

Data Availability Statement: Not applicable. 
Conflicts of Interest: The authors declare no conflict of interest.

\section{References}

1. Albuquerque, B.R.; Heleno, S.A.; Oliveira, M.B.P.; Barros, L.; Ferreira, I.C. Phenolic compounds: Current industrial applications, limitations and future challenges. Food Funct. 2021, 12, 14-29. [CrossRef]

2. Fernández-Ruiz, V.; Morales, P.; Ruiz-Rodríguez, B.M.; TorijaIsasa, E. Nutrients and bioactive compounds in wild fruits through different continents. In Wild Plants, Mushrooms and Nuts: Functional Food Properties and Applications; John Wiley \& Sons, Ltd.: Hoboken, NJ, USA, 2017; pp. 263-314.

3. Pieroni, A.; Nedelcheva, A.; Dogan, Y. Local knowledge of medicinal plants and wild food plants among Tatars and Romanians in Dobruja (South-East Romania). Genet. Resour. Crop Evol. 2015, 62, 605-620. [CrossRef]

4. Lattanzio, F.; Greco, E.; Carretta, D.; Cervellati, R.; Govoni, P.; Speroni, E. In vivo anti-inflammatory effect of Rosa canina L. extract. J. Ethnopharmacol. 2011, 137, 880-885. [CrossRef]

5. Kirkeskov, B.; Christensen, R.; Bügel, S.; Bliddal, H.; Danneskiold-Samsøe, B.; Christensen, L.P.; Andersen, J.R. The effects of rose hip (Rosa canina) on plasma antioxidative activity and C-reactive protein in patients with rheumatoid arthritis and normal controls: A prospective cohort study. Phytomedicine 2011, 18, 953-958. [CrossRef] [PubMed]

6. Bedreag, C.F.G.; Trifan, A.; Bucur, L.A.; Arcus, M.; Tebrencu, C.; Miron, A.; Costache, I.I. Chemical and antioxidant studies on Crataegus pentagyna leaves and flowers. Rom. Biotechnol. Lett. 2014, 19, 9859.

7. Chang, Q.; Zuo, Z.; Harrison, F.; Chow, M.S.S. Hawthorn. J. Clin. Pharmacol. 2002, 42, 605-612. [CrossRef]

8. Sikora, E.; Bieniek, M.I.; Borczak, B. Composition and antioxidant properties of fresh and frozen stored blackthorn fruits (Prunus spinosa L.). Acta Sci. Pol. Technol. Aliment. 2013, 12, 365-372.

9. Guarrera, P.M. Food medicine and minor nourishment in the folk traditions of Central Italy (Marche, Abruzzo and Latium). Fitoterapia 2003, 74, 515-544. [CrossRef]

10. Mihailović, N.R.; Mihailović, V.B.; Kreft, S.; Ćirić, A.R.; Joksović, L.G.; Đurđević, P.T. Analysis of phenolics in the peel and pulp of wild apples (Malus sylvestris (L.) Mill.). J. Food Compost. Anal. 2018, 67, 1-9. [CrossRef]

11. Savić, A.; Alimpić Aradski, A.; Duletić Laušević, S.; Marin, P. Antioxidant activity, phenolic and flavonoid contents of methanol extract of Pyrus pyraster fruit. In Proceedings of the 6th Balkan Botanical Congress, Rijeka, Croatia, 14-18 September 2015. Available online: http:/ / hdl.handle.net/123456789/2133 (accessed on 10 October 2021).

12. Egea, T.; Signorini, M.A.; Bruschi, P.; Rivera, D.; Obón, C.; Alcaraz, F.; Palazón, J.A. Spirits and liqueurs in European traditional medicine: Their history and ethnobotany in Tuscany and Bologna (Italy). J. Ethnopharmacol. 2015, 175, 241-255. [CrossRef] [PubMed]

13. Güler, B.; Manav, E.; Uğurlu, E. Medicinal plants used by traditional healers in Bozüyük (Bilecik-Turkey). J. Ethnopharmacol. 2015, 173, 39-47. [CrossRef] [PubMed]

14. Leporatti, M.L.; Ivancheva, S. Preliminary comparative analysis of medicinal plants used in the traditional medicine of Bulgaria and Italy. J. Ethnopharmacol. 2003, 87, 123-142. [CrossRef]

15. Cosmulescu, S.; Cornescu, F. Variability in physical and chemical characteristics of Cornelian cherry fruits (Cornus mas L.) from Romanian Oltenia region's spontaneous flora and role of the climatic conditions. Rev. Bras. Bot. 2020, 43, 677-682. [CrossRef]

16. Cosmulescu, S.N.; Trandafir, I.; Cornescu, F. Antioxidant capacity, total phenols, total flavonoids and colour component of cornelian cherry (Cornus mas L.) wild genotypes. Not. Bot. Horti Agrobot. Cluj-Napoca 2019, 47, 390-394. [CrossRef]

17. Dinda, B.; Kyriakopoulos, A.M.; Dinda, S.; Zoumpourlis, V.; Thomaidis, N.S.; Velegraki, A.; Dinda, M. Cornus mas L. (cornelian cherry), an important European and Asian traditional food and medicine: Ethnomedicine, phytochemistry and pharmacology for its commercial utilization in drug industry. J. Ethnopharmacol. 2016, 193, 670-690. [CrossRef]

18. Nizioł-Łukaszewska, Z.; Wasilewski, T.; Bujak, T.; Gaweł-Bęben, K.; Osika, P.; Czerwonka, D. Cornus mas L. extract as a multifunctional material for manufacturing cosmetic emulsions. Chin. J. Nat. Med. 2018, 16, 284-292. [CrossRef]

19. Mechchate, H.; Es-Safi, I.; Haddad, H.; Bekkari, H.; Grafov, A.; Bousta, D. Combination of catechin, epicatechin, and rutin: Optimization of a novel complete antidiabetic formulation using a mixture design approach. J. Nutr. Biochem. 2021, 88, 108520. [CrossRef] [PubMed]

20. Binang, K.; Takuwa, D.T. Development of reverse phase-high performance liquid chromatography (RP-HPLC) method for determination of selected antihypertensive active flavonoids (rutin, myricetin, quercetin, and kaempferol) in medicinal plants found in Botswana. Phys. Sci. Rev. 2021. [CrossRef]

21. Cosmulescu, S.; Trandafir, I.; Nour, V. Phenolic acids and flavonoids profiles of extracts from edible wild fruits and their antioxidant properties. Int. J. Food Prop. 2017, 20, 3124-3134. [CrossRef]

22. Shebeko, S.K.; Zupanets, I.A.; Popov, O.S.; Tarasenko, O.O.; Shalamay, A.S. Effects of quercetin and its combinations on health. In Polyphenols: Mechanisms of Action in Human Health and Disease; Academic Press: Cambridge, MA, USA, 2018 ; pp. 373-394.

23. Abdulkhaleq, L.A.; Assi, M.A.; Noor, M.H.M.; Abdullah, R.; Saad, M.Z.; Taufiq-Yap, Y.H. Therapeutic uses of epicatechin in diabetes and cancer. Vet. World 2017, 10, 869-872. [CrossRef]

24. Veličković, J.M.; Kostić, D.A.; Stojanović, G.S.; Mitić, S.S.; Mitić, M.N.; Ranđelović, S.S.; Đorđević, A.S. Phenolic composition, antioxidant and antimicrobial activity of the extracts from Prunus spinosa L. fruit. Hem. Ind. 2014, 68, 297-303. [CrossRef]

25. Viapiana, A.; Wesolowski, M. The phenolic contents and antioxidant activities of infusions of Sambucus nigra L. Plant Foods Hum. Nutr. 2017, 72, 82-87. [CrossRef] [PubMed] 
26. Dawidowicz, A.L.; Wianowska, D.; Baraniak, B. The antioxidant properties of alcoholic extracts from Sambucus nigra L. (antioxidant properties of extracts). Food Sci. Technol. 2006, 39, 308-315. [CrossRef]

27. Contardi, M.; Lenzuni, M.; Fiorentini, F.; Summa, M.; Bertorelli, R.; Suarato, G.; Athanassiou, A. Hydroxycinnamic acids and derivatives formulations for skin damages and disorders: A review. Pharmaceutics 2021, 13, 999. [CrossRef]

28. Kahkeshani, N.; Farzaei, F.; Fotouhi, M.; Alavi, S.S.; Bahramsoltani, R.; Naseri, R.; Bishayee, A. Pharmacological effects of gallic acid in health and diseases: A mechanistic review. Iran J. Basic Med. Sci. 2019, 22, 225. [PubMed]

29. Oszmiański, J.; Wojdyło, A.; Nowicka, P.; Teleszko, M.; Cebulak, T.; Wolanin, M. Determination of phenolic compounds and antioxidant activity in leaves from wild Rubus L. species. Molecules 2015, 20, 4951-4966. [CrossRef]

30. Andreotti, C.; Costa, G.; Treutter, D. Composition of phenolic compounds in pear leaves as affected by genetics, ontogenesis and the environment. Sci. Hortic. 2006, 109, 130-137. [CrossRef]

31. Li, X.; Wang, T.; Zhou, B.; Gao, W.; Cao, J.; Huang, L. Chemical composition and antioxidant and anti-inflammatory potential of peels and flesh from 10 different pear varieties (Pyrus spp.). Food Chem. 2014, 152, 531-538. [CrossRef] [PubMed]

32. Demir, N.; Yildiz, O.; Alpaslan, M.; Hayaloglu, A.A. Evaluation of volatiles, phenolic compounds and antioxidant activities of rose hip (Rosa L.) fruits in Turkey. LWT Food Sci. Technol. 2014, 57, 126-133. [CrossRef]

33. Olennikov, D.N.; Vasilieva, A.G.; Chirikova, N.K. Fragaria viridis fruit metabolites: Variation of LC-MS profile and antioxidant potential during ripening and storage. Pharmaceuticals 2020, 13, 262. [CrossRef] [PubMed]

34. Srinivasulu, C.; Ramgopal, M.; Ramanjaneyulu, G.; Anuradha, C.M.; Kumar, C.S. Syringic acid (SA)—A review of its occurrence, biosynthesis, pharmacological and industrial importance. Biomed. Pharmacother. 2018, 108, 547-557. [CrossRef] [PubMed]

35. Nićiforović, N.; Abramovič, H. Sinapic acid and its derivatives: Natural sources and bioactivity. Compr. Rev. Food Sci. Food Saf. 2014, 13, 34-51. [CrossRef] [PubMed] 